\title{
RESTRIÇÕES DE PREDICAÇÃO EM JAPONÊS: O LUGAR DO SUJEITO NA GRAMÁTICA DA NARRATIVA*
}

\author{
MARY AIZAWA KATO \\ (UNICAMP)
}

\begin{abstract}
This work contributes to the long term discussion between those that defend the formal linguistic clues as the main source of meaning apprehended by the reader and those that consider reading as a product of the reader's creation. A curious linguistic fact in Japanese will be used as an argument towards the first position. Predicates that denote internal human states, like sad and tired, cannot be used with second and third person pronouns in Japanese, unless they are used by an omniscient author of a narrative, who can violate this norm for empathy reasons. The paper suggests that in languages like English there are also subtle linguistic clues to convey the author's attitude towards his characters.
\end{abstract}

Com o desenvolvimento dos estudos da pragmática no âmbito da lingüística teórica e do interesse pelas pesquisas empíricas em leitura na área da lingüística aplicada, vimos presenciando um debate acalorado entre a posição que enfatiza o objeto textual como fonte de significado e a que supõe ser o sujeito leitor o agente criador de significados.

Minha posição, em relação a esta polêmica, advém de minha concepção chomskiana de língua e, coerentemente com essa concepção, acredito que a representação abstrata de uma forma lingüística contém aquilo que se convencionou chamar de 'forma lógica', para se distinguir da expressão 'representação semântica', excessivamente abrangente, que permitia atribuir à forma lingüística toda a interpretação semântica da sentença, através da forma lógica. A forma lógica, por sua vez, que é mapeada diretamente da estrutura sintática, é considerada, na concepção atual de gramática, como a interface da sintaxe com outros sistemas de conhecimento, de tal sorte que a representação semântica global de uma forma lingüística teria, em sua forma lógica, apenas um dos elementos para sua determinação. Embora acredite que a contribuição da forma lógica seja bastante restrita, acredito também que muito do que hoje se atribui ao contexto ou à ideologia e crenças do sujeito e não à gramática pode ser, na verdade, uma função da forma.

Neste trabalho pretendo examinar uma questão de predicação peculiar do japonês que nos permitirá abrir uma discussão concreta sobre a relação entre forma lingüística e significado.

\footnotetext{
* Trabalho apresentado em mesa-redonda sobre O Sujeito, Unicamp, 1986.
} 
Em português e em outras línguas ocidentais, podemos fazer as seguintes asserções com adjetivos de sensação:
(1) a. Eu estou triste.
b. Você está triste
c. Ele está triste.

Em japonês, a asserção com esse tipo de predicado só é possível em situação normal de conversação para a primeira pessoa:
(2) a. Watakushi-wa kanashii.
b. *Anata-wa kanashii.
c. *Kare-wa kanashii.

Para atribuir tal tipo de estado à segunda ou terceira pessoa uma forma verbal com o mesmo radical deve ser usada. Essa forma, por sua vez, não pode ser usada para a primeira pessoa.
(3) a. *Watakushi-wa kanashigatte-iru.
b. Anata-wa kanashigatte-iru.
c. Kare-wa kanashigatte-iru.

Segundo Kuroda (1973), tais predicados são epistemologicamente diferentes de adjetivos como alto ou quadrado. Juízos que contêm predicados desse tipo expressam fatos que podem ser falsos ou verdadeiros enquanto que aqueles que contêm adjetivos como 'kanashii' (triste), 'atsui' (quente), 'sabishii' (solitário) etc., expressam estados do falante que não são passíveis de serem julgados como verdadeiros ou falsos. Por outro lado, a forma verbal que eqüivale a dizer 'está agindo como se estivesse triste', é passível de ser constatada como um fato verdadeiro ou falso pelos sinais externos que o sujeito apresenta do estado interior.

Curiosamente, esse é um fenômeno que só afeta orações principais e orações não-modalizadas, isto é, ele não afeta aquelas formas que Kuroda chama de asserções de segunda ordem.

Outro contexto em que a segunda e terceira pessoas do discurso não constituem impedimentos para o uso desses predicados, embora Kuroda não o mencione, é o das perguntas. Assim, posso perguntar a X se $\mathrm{X}$ ou $\mathrm{Y}$ está triste, mas não posso expressar que $\mathrm{X}$ ou Y esteja triste.

O interesse desses predicados não está apenas no uso que Kuroda chama de paradigmático, e que estamos chamando de situação normal de conversação, mas na forma como esses predicados são utilizados na literatura, já que é esse o lugar privilegiado de se expressar estados não apenas do falante ou do narrador mas também dos personagens.

Kuroda separa o discurso da narrativa em dois tipos: a) reportativo e b) não-reportativo.

O reportativo é aquele em que o narrador, como personagem ou não, esta onipresente, mas é um mero expectador, isto é, não tem propriedades extra-humanas de dizer o que os outros personagens estão sentindo. Logo, se o estilo é reportativo, o 
narrador usará a forma verbal dos predicados de sensação, que é dedutiva e não expressiva.

O não-reportativo é aquele em que o narrador é o próprio personagem e pode diretamente expressar seus estados .

Há, na literatura, porém, exemplos freqüentes em que a narrativa assume a forma adjetiva e não verbal, na descrição dos estados dos personagens. Kuroda levanta a hipótese, então do narrador onisciente, que, devido às suas capacidades extra-humanas, pode violar a regra de uso desses adjetivos. Essa tese se coaduna, a meu ver, com a visão ideológica que atribui ao sujeito do discurso a autoridade de violar as regras da gramática. Se essa tese for verdadeira, seria de se esperar que uma vez que a narrativa se desenvolve através do narrador 'onisciente', o estilo seria homogeneamente não-reportativo. Mas não é o que ocorre. Kuroda mostra que o narrador freqüentemente muda a perspectiva da narrativa de um sujeito para outro, podendo este ser um personagem ou o narrador onipresente. Um exemplo que ele dá para ilustrar suas idéias em inglês está em um trecho do livro Sons and Lovers de Lawrence:

Paul looked into Miriam's eyes. She was pale and expectant with wonder, her lips were parted, and her dark eyes lay open to him. His look seemed to travel down into her. Her soul quivered. It was the communion she wanted. He turned aside as if pained. He turned to the bush.

Kuroda diz que, nesse trecho, há mudanças de perspectiva, que revelam a existência de múltiplas consciências, isto é, o trecho é uma coleção estruturada da consciência de vários sujeitos. Para Kuroda é justamente a existência na gramática de duas formas para expressar estados de conhecimento diferentes que nos permite perceber essas mudanças de perspectiva. Kuroda não analisa, no texto em inglês, o que sinalizaria essas mudanças, pois seu objetivo é mostrar como essas restrições do uso paradigmático da gramática do japonês podem ser um subsídio importante para o estudo do estilo narrativo. É interessante observar, contudo, que a sexta sentença do trecho apresenta uma forma de predicação que se assemelha muito à forma verbal dos predicados de estado em japonês: ‘ He turned aside as if pained'. Nota-se que o autor não disse: 'He felt pain' ou 'He pained '. Ele mostra um comportamento do personagem que revela seu estado de dor. Logo, por essa forma, podemos deduzir que o estado de dor de Paul não está presente na consciência do narrador. O que existe é a descrição do narrador omnipresente ou a consciência de Miriam sobre o estado de Paul. Por outro lado, a consciência da alma estremecendo só pode ser diretamente experienciada por Miriam, donde é justificado dizer que a narrativa é feita da perspectiva desta última.

A importância desse estudo de Kuroda está na reflexão que ele provoca sobre a questão polêmica da relação entre forma lingüística e o sujeito interpretante ou leitor. Como já dissemos, no início, para muitos estudiosos da leitura, o texto escrito tem pouca autonomia de significação, sendo o sujeito leitor o lugar onde o significado se constitui. $\mathrm{O}$ problema da reconstituição lingüística das intenções, perspectivas e empatias do leitor é posta em dúvida por esses estudiosos, com a alegação de que a forma linguiística é necessariamente vaga e indeterminada, havendo, na verdade, mais um processo de construção de significado pelo leitor do que de reconstituição do significado pretendido pelo escritor. 
Kuroda, em seu trabalho, diz que a gramática do estilo reportativo e não-reportativo difere em japonês no que diz respeito aos predicados de sensação, o que é de se esperar dada a epistemologia desses predicados. Contudo, segundo o autor, não é apenas esse aspecto que configura a gramática do estilo reportativo ou não-reportativo. $\mathrm{O}$ uso da reflexivização nos textos mostra também claramente a perspectiva do narrador. O leitor japonês, ao ler um texto, deverá guiar-se inconscientemente por essas pistas para construir o significado do texto. E é o linguista, com sua metodologia laboratorial e suas idealizações, que consegue explicar aquilo que percebemos inconscientemente. A não consciência desses fatos pode levar-nos a acreditar que a construção do significado se fez a partir de nós sujeitos leitores, quando na verdade o texto abriga as pistas que viabilizaram a a interpretação conferida. A descoberta desse tipo de pista em nossa língua é um trabalho a ser empreendido pois como diz Kuroda "a língua revela várias facetas de nossa mente, mas não necessariamente da mesma forma em todas as línguas". É nessa diversidade que reside o fascínio do estudo das línguas.

\section{REFERÊNCIAS}

KURODA, S-Y. (1973). "Where epistemology, style and grammar meet”. In A.Anderson \& P Kiparski (orgs) A Festschrift for Morris Halle. Holt, New York: Rinehart \& Winston.

LAWRENCE, H.D. (1999). Sons and Lovers. Penguin. Modern Library, original de 1913. Edição consultada.New York: Modern Library. 